\title{
Intermittent Androgen Suppression Therapy for Prostate Cancer Patients: A Choice for Improved Quality of Life?
}

\author{
Gerhard Hamilton ${ }^{1}$, Ulrike Olszewski-Hamilton ${ }^{1}$ and Gerhard Theyer ${ }^{2}$ \\ ${ }^{1}$ Ludwig Boltzmann Cluster of Translational Oncology, Vienna \\ ${ }^{2}$ LKH Kittsee, Burgenland \\ Austria
}

\section{Introduction}

Prostate cancer is among the most common types of malignancies and causes of cancerrelated deaths in men worldwide (Fitzpatrick, et al., 2009). Primary tumor involvement outside the prostatic capsule or relapse following radical prostatectomy results generally in incurability (Lassi \& Dawson, 2009). Androgen deprivation therapy has progressed since attempts in 1941, when surgical castration had been shown to improve outcomes for the first time. Palliative treatment consists of hormonal manipulation to deprive the cancer cells of androgenic stimulation by orchidectomy or use of LHRH analogs and steroidal or nonsteroidal antiandrogens (Kollmeier \& Zelefsky, 2008). Although continuous androgen suppression therapy (CAS) has been a cornerstone of the management of prostate cancer for more than 50 years, controversy remains regarding its optimum application. Generally, androgen suppression (AS) is performed as continuous treatment, resulting in apoptotic regression of the tumor cells in a high percentage of cases. However, surgical or medical castration results in median progression-free survival of only 2-3 years, with no other effective treatment left (Mellado, et al., 2009). Responses to cytotoxic therapy are low and only recently several studies revealed a possible benefit of incorporating chemotherapeutic agents in treatment regimen for prostate cancer (Chang \& Kibel, 2009). Taxanes like docetaxel and cabazitaxel, therapeutic cancer vaccines and newly developed agents targeting androgen receptor signaling are expected to improve therapy (Madan et al., 2011).

Following experimental research using animal models, intermittent androgen suppression (IAS) was introduced as new clinical concept, assuming that during limited regrowth in the treatment cessation periods tumorigenic cells are residing in an androgen-responsive state (Goldenberg, et al., 1995). Since induction of androgen independence may occur early after treatment initiation, cessation of antiandrogen therapy prior to this switch is expected to maintain the apoptotic potential of the tumor cells and keep them sensitive to retreatment. Providing an easy method for selection of the type of treatment and early assessment of tumor growth during the off-periods serial serum PSA determinations made IAS feasible. In detail, IAS consists of an initial androgen suppression period of up to nine months combining LHRH antagonists and antiandrogens, which is followed by treatment cessation 
until a certain PSA threshold is reached; then, androgen suppression is reinitiated until a maximal effect is observed again. In initial pilot trials regrowing tumors of patients undergoing IAS were consistently reported to be sensitive over several cycles of androgen withdrawal (figure 1).

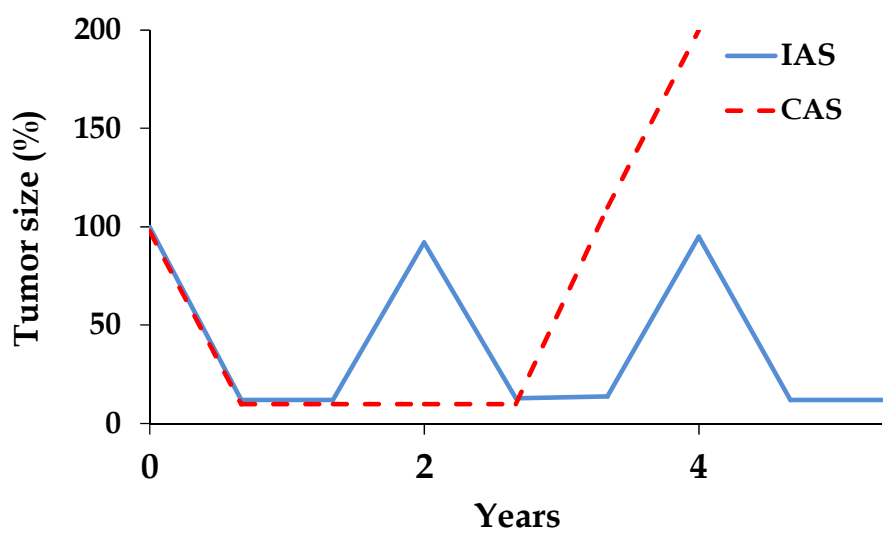

Fig. 1. Schematic model of CAS and IAS. CAS treatment of prostate cancer rapidly results in appearance of androgen-insensitive cells and tumor progression within 2-3 years in advanced stages. On the contrary, IAS preserves the hormone sensitivity of the cells through cycling between androgen suppression and treatment cessation phases in order to prolong the time to hormone refractoriness and possibly survival.

Therefore, the primary goal of IAS has been the prolongation of the hormone-sensitivity of the tumors, which in turn has been expected to result in increased survival eventually. Based on the available evidence, IAS nowadays represents a valid treatment option for patients with nonmetastatic prostate cancer, including those with locally advanced disease, either with or without lymph node involvement, and those who relapsed following apparently curative treatment. IAS has been researched since the mid-1980s in a number of clinical phase II and III trials in an effort to prolong hormone-dependency and reduce adverse effects and costs of CAS (Goldenberg, et al., 1995; Bales, et al., 1996; Buchan \& Goldenberg, 2010, da Silva, 2011). With preclinical evidence suggesting a potential benefit of IAS in terms of time to androgen independence, with phase II and phase III studies producing optimistic results and with the potential for decreased costs and complications, IAS has now become a popular modality of therapy worldwide.

\section{Experimental development of intermittent androgen suppression}

The concept of IAS was experimentally developed using the androgen-dependent Shionogi mouse mammary tumor, investigating regular phases of growth, regression and recurrence of xenograft tumors during serial transplantation (Bruchovsky, et al., 1985). Since postcastrational progression of tumors towards an androgen-independent state appears to be linked to the cessation of androgen-induced differentiation of tumorigenic stem cells, it was hypothesized that the replacement of androgens at the end of apoptotic regression might result in the reappearance of differentiated tumor cells that maintain their apoptotic 
potential. To determine the effect of intermittent application of androgens on the androgendependent Shionogi carcinoma, the tumor was transplanted into a succession of male mice, each of which was castrated when the estimated tumor weight became about $3 \mathrm{~g}$. After the tumor had regressed to $30 \%$ of the original weight, it was transplanted into the next noncastrated male (Akakura, et al., 1993). This cycle of transplantation and castrationinduced regression was successfully repeated four times before tumor growth became androgen-independent during the fifth cycle (figure 2).

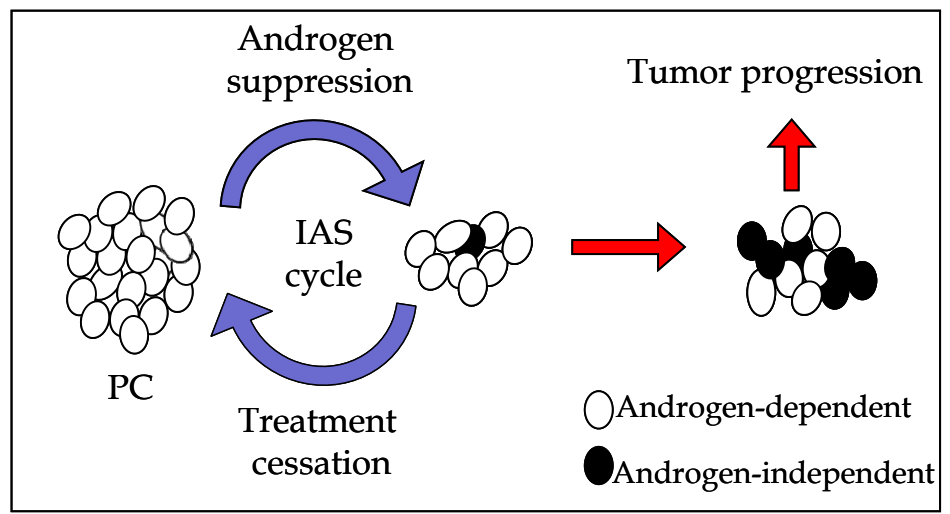

Fig. 2. Experimental animal model of IAS using androgen-dependent Shionogi tumor cells. Tumor cells are androgen-depleted by castration and, following tumor shrinkage to a defined degree, treatment cessation re-establishes a hormone-sensitive tumor. This cycle can be repeated four times until androgen-insensitive cells constitute a population of approximately $50 \%$ of all tumor cells in the fifth cycle and progression to a hormonerefractory tumor occurs.

The average duration of one cycle was 30 days and progression to androgen-insensitivity was observed after 150 days. After castration, the concentration of testosterone in the tumor was demonstrated to decline more rapidly than the dihydrotestosterone levels and spontaneous recurrent growth was not accompanied by significant elevation of the wholetissue concentration of either androgen. These results suggested that a recurrent tumor may contain hormone-sensitive cells, which are capable of resuming growth in an androgendepleted environment. The data also imply that progression from the androgen-dependent to the androgen-autonomous condition involves the selection and outgrowth of heterogeneous hormone-insensitive cells.

The effects of castration on gene expression were measured in the androgen-dependent Shionogi mouse tumor model (Rennie, et al., 1988). During the first $48-72 \mathrm{~h}$ after castration, the tumor continued to increase its mass, but began to regress at 72-144 $\mathrm{h}$. In the surviving cells there were no major decreases in RNA synthesis. Under these conditions, selected genes become overexpressed and, in particular, the concentration of the transcripts encoding testosterone-repressed prostate message-2 (TRPM-2/clusterin) was enhanced only when tumor regression was most evident, i.e. 72-144 $\mathrm{h}$ after castration. The TRPM-2 (clusterin) gene also became expressed constitutively in non-regressing tumors after the first and subsequent cycles of androgen withdrawal. TRPM-2 is a membrane-stabilizing protein that appears to be involved in limiting the autophagic lysis of epithelial cells during 
apoptosis and is possibly preserving the nuclear environment, suppressing the lethal effect of anti-androgenic treatment (Akakura, et al., 1993). Therefore, tumor progression, characterized by the loss of the apoptotic potential, appears to be linked in part to the inappropriate activation of the TRPM-2 gene.

Since postcastrational progression of tumors to an androgen-independent state appears to be linked to the cessation of androgen-induced differentiation of tumorigenic stem cells, the replacement of androgens at the end of a period of apoptotic regression might result in the regeneration of differentiated tumor cells with maintained apoptotic potential. (Akakura, et al., 1993). The frequency of androgen-dependent and -independent tumorigenic stem cells in parent and recurrent Shionogi tumors was determined with help of an in vivo limiting dilution test (Rennie, et al., 1990). When assayed in male hosts a marked enrichment of stem cells in the recurrent tumors (1/200 tumor cells) relative to the parent tumors $(1 / 4000$ tumor cells) was detectable. By measuring tumor takes in female mice, a 500-fold increase in androgen-independent stem cells was found in the recurrent carcinoma. No enrichment of androgen-independent stem cells was evident in regressing parent tumors. This finding implies that the androgen-independent cells that survived androgen-withdrawal may result from the ability of a small number of initially androgen-independent stem cells to adapt to an altered hormonal environment. These results again indicated that the tumor mass mainly consisted of differentiated cells and that stem cells are initially androgen-dependent, but the apoptosis-inducing effect of androgen withdrawal will be limited to a factor of 100-1000, before compensatory adaptive mechanisms lead to progression of stem cells to an androgen-independent state. In recurrent tumors the amount of dihydrotestosterone was reduced by approximately $85 \%$ in comparison to the parent tumor and expression of nuclear androgen receptor was completely abolished within $24 \mathrm{~h}$ after castration (Bruchovsky, et al., 1990). However, later on the amount of androgen receptor mRNA in androgen-dependent and -independent cells derived from the Shionogi carcinoma was similar, showing no relationship to progression (Akakura, et al., 1996). The uncoupling of TRPM-2 expression and apoptosis observed in androgen-independent tumor cells implicates that the function of androgen receptor becomes more restricted with tumor progression. There is evidence that the androgen receptor still plays an important role in progression to the castration-resistant incurable state in prostate cancer. While castration proved to be ineffective in castrationresistant prostate tumors in an animal model, knockdown of androgen receptor was demonstrated to decrease serum PSA, inhibit cancer growth and frequently resulted in tumor regression (Snoek, et al., 2009). This study provided evidence that elimination of the androgen receptor might constitute a promising therapeutic strategy for treatment of prostate tumors that had progressed to the castration-resistant state.

Serial determinations of the proportion of stem cells in the Shionogi tumor revealed a constant part during the first three cycles but a 15-fold increase between the third and fourth cycles (Rennie, et al., 1994). In the parent androgen-dependent tumor before androgen ablation they formed $0.8 \%$ of the total stem cell compartment. After the fourth cycle the androgen-independent stem cell population increased to $47 \%$ and a population of similar size was found in the androgen-independent recurrent of the tumor, which was induced by one-time castration. Therefore, it was concluded that independent of intermittent or continuous androgen withdrawal, conversion to hormone-insensitivity occurs as soon as the tumor has accumulated one-third to one-half of the total stem cell compartment with androgen-independent cells. 
The next step included the switch to a human prostate cancer xenograft model using the LNCaP androgen-dependent prostate cell line, where serum PSA levels correlated well with tumor volume and decreased rapidly after castration, followed by appearance of androgenindependency after 3-4 weeks (Gleave, et al., 1996). IAS-treated mice were implanted with testosterone pellets two weeks after castration and were subjected to cycles of testosterone replacement for 1 week and withdrawal for 2 weeks until serum PSA levels returned to baseline no longer. IAS therapy prolonged time to androgen-independent PSA production 3 -fold, from an average of 26 days in the CAS group to 77 days in the IAS group. It was concluded that IAS in the LNCaP model delayed the onset of androgen-independent PSA gene regulation markedly most likely due to androgen-induced differentiation and/or downregulation of androgen-suppressed gene expression. In summary, the animal experimental data indicated that androgen-dependent tumor xenografts can be subjected to several cycles of androgen withdrawal/replacement and revealed prolonged hormonedependency compared to continuous androgen suppression.

\section{Clinical development of intermittent androgen suppression}

Since the introduction of PSA screening in the late 1980s, more prostate cancers have been detected, and at an earlier stage (Gjertson \& Albertsen, 2011). Consequently, the majority of prostate cancers are now detected years before the emergence of clinically evident disease, which usually represents locally advanced or metastatic cancer. PSA screening has remained controversial, because many of the prostate cancers detected are low grade and slow growing and will not need aggressive therapy. Prostate cancer is biologically and clinically a heterogeneous malignancy and its imaging evaluation will need to be tailored to the specific phases of the disease in a patient-specific, risk-adapted manner (Jadvar, 2011). With this long natural history and a median survival without treatment that often approaches at least 15-20 years, many patients will die rather with than of prostate cancer. Approximately onethird of patients who undergo radical prostatectomy will develop a detectable PSA level within 10 years (Tzou, et al., 2011). Biochemical relapse is defined as a rising PSA level in the absence of clinical or radiographic evidence of tumor. Management of PSA recurrence is controversial, as prostate cancer may take an indolent course, or it may develop aggressively into metastatic disease. The only potentially curative treatment for biochemical failure after prostatectomy is radiotherapy and the other treatment options include hormone therapy or clinical trials of new agents.

Research on hormonal treatment of prostate cancer over the past 20 years has focused on maximizing androgen ablation through combination therapy. This increases treatmentrelated side-effects and expenses and fails to prolong time to progression to androgenindependence (Gleave, et al., 1998, Kollmeier \& Zelefsky, 2008 ). Preliminary evidence indicates that a low androgen milieu is associated with tumor aggressiveness. Transition to androgen-independence is a complex process and involves both selection and outgrowth of preexisting androgen-resistant clones as well as adaptative upregulation of genes that enable cancer cells to survive and grow after CAS (Corona, et al., 2011). CAS in men with prostate cancer increases the risk of osteoporotic fractures, type 2 diabetes and, possibly, cardiovascular events (Grossmann, et al., 2011). The benefits of CAS in treating nonmetastatic prostate cancer need to be carefully weighed against the risks of CAS-induced adverse events. Management of the metabolic sequelae of CAS includes optimal reduction 
of cardiovascular risk factors, with particular attention to weight, blood pressure, lipid profile, smoking cessation and glycemic control.

The rationale behind IAS is based on the hypothesis that, if tumor cells, which survive androgen withdrawal, are forced into a normal differentiation pathway by androgen replacement, their apoptotic potential might be restored and progression to androgen independence may be delayed. Furthermore, immediate androgen ablation can be accomplished with less side effects and quality of live can be improved in a palliative setting. Observations from animal model studies suggest that progression to androgenindependence involves adaptive responses to androgen deprivation, which seem to be delayed by intermittent androgen replacement. Supported by these results, several centers tested the feasibility of IAS in non-randomized groups of prostate cancer patients with serum PSA as trigger point (Buchan \& Goldenberg, 2010).

For example, in a small pilot trial in four stage $C$ and three stage $D$ patients with prostate cancer androgen withdrawal was initiated with cyproterone acetate and diethylstilbestrol and then maintained with cyproterone acetate in combination with the LHRH agonist goserelin acetate (Akakura, et al., 1993). After 6 or more months of suppression, treatment was interrupted for 2-11 months. After recovery of testicular function, androgen-withdrawal was resumed when serum PSA increased to a level of about $20 \mathrm{ng} / \mathrm{ml}$. This cycle was sequentially repeated to a total of 2-4 times over treatment periods of $21-47$ months with no loss of androgen-dependence. These early results demonstrate that IAS can be used to induce multiple apoptotic regressions of a tumor.

Overall, these trials suggest that IAS is neither inferior nor superior to CAS, with respect to time to castration resistance and cancer-specific survival, but has significant advantages in terms of adverse effects, quality of life and costs (Buchan \& Goldenberg, 2010). A number of unresolved questions remain regarding patient selection for therapy, optimum duration of treatment, optimal time point of reinitiation oftherapy after the off-phase and definition of progression to castration-resistant disease. In future, the use of second-line drugs during offtreatment phases holds potential for delaying disease progression in men undergoing IAS. In a review data from 19 phase II studies were discussed with respect to PSA values for treatment suspension/reinitiation, treatment regimen, cycle lengths, testosterone normalization and tolerability. Most trials reported an improvement in quality of life during the off-therapy periods. Interim data from 8 phase III trials comparing IAS and CAS were found to corroborate the phase II results (Abrahamsson, 2009). Phase II/III data suggested that IAS was as effective as CAS but was characterized by better tolerability and quality-oflife advantages; however, more data are required to determine the effect of IAS on the longterm complications of androgen deprivation. Disease progression in 96 patients with biochemically relapsed prostate cancer under IAS was associated with pretreatment PSA doubling time (PSADT) $\geq 6$ vs. $<6$ months, first off-treatment interval PSADT of $\geq 3$ vs. $<3$ months and PSA nadir during the first treatment interval of $<0.1 \mathrm{vs}$. $\geq 0.1 \mathrm{ng} / \mathrm{ml}$. During IAS PSADT became shorter and was associated with testosterone recovery (Keizman, et al., 2011). The duration of the first off-treatment interval (< or $>40$ weeks) was correlated with shorter time to hormone-insensitivity and death after adjusting for age, stage, grade and PSA at diagnosis (Yu et al., 2010, Sciarra, et al., 2011).

Few randomized studies compared IAS with CAS for the treatment of advanced prostate cancer. Early survival results from phase III trials were limited and inconsistent. Mottet and colleagues reported no significant difference between patients receiving IAS and CAS with respect to median overall survival and median progression-free survival (Mottet, et al., 2006). 
In another IAS study, 127 patients from the intermittent arm and 107 patients from the continuous arm progressed, with a hazard ratio (HR) of 0.81 (da Silva, et al., 2009). There was no difference in survival, with a HR of 0.99 . The greater number of cancer deaths in the IAS arm (106 vs 84) was balanced by a greater number of cardiovascular deaths in the continuous arm (52 vs 41 ). Side effects were more pronounced in the continuous arm and patients treated with IAS reported better sexual function. Median time off therapy for the IAS-treated patients was 52 weeks. However, significant differences were reported in one study: de Leval and colleagues published that the estimated risk of 3-year progression in CAS patients was significantly higher than in the IAS group. This difference was highlighted in patients with a Gleason score $>6$, where the 3-year progression rates were significantly higher in CAS rather than in IAS patients (de Leval, et al., 2002). Large phase III clinical trials of intermittent vs continuous androgen deprivation in men with metastatic disease or recurrent disease after localized therapy were requested for more than 2 decades in order to obtain reliable data for the comparative impact of these therapies on quality of life and survival.

Finally, the Intergroup randomized phase III trial, which compared IAS vs CAS to test for non-inferiority of IAS with respect to overall survival was presented in February 2011 (Klotz, et al., 2011). Eligible men had rising PSA $>3.0 \mathrm{ng} / \mathrm{ml}>1$ year post irradiation that was either initial or salvage for treatment of localized prostate cancer. IAS was delivered for 8 months in each cycle with restart when PSA reached $>10 \mathrm{ng} / \mathrm{ml}$ in the off-treatment phase. Primary endpoint was overall survival (OS); secondary endpoints included time to hormone refractory state, quality of live, duration of treatment/non-treatment intervals and time to recovery of testosterone and potency. 1,386 patients were randomized to IAS (690) or CAS (696) arms and median follow-up was 6.9 years. IAS patients completed a median of $2 \times 8$ months cycles (range: 1-9). Median OS was 8.8 vs 9.1 years in IAS and CAS arms, respectively, with more disease-related (122 vs 97) in the IAS and fewer disease-unrelated (134 vs. 146) deaths in the CAS arm. Time to hormone resistance was statistically significantly improved in the IAS arm (HR 0.80, $\mathrm{p}=0.024)$. Time to development of castration resistance was close to 10 years and in favour of IAS, but the trial design was biased towards IAS. In order to achieve castration resistance status, patients had to be being on treatment. Therefore, some patients who had a rising PSA off-treatment may in fact have had castration-resistant disease, but treatment had to be restarted and the PSA seen to continue to rise before this status could be defined. IAS patients had reduced occurrences of hot flashes, but there was no evidence of differences in adverse events, including myocardial problems or osteoporotic fractures. Thus, in men with PSA recurrence after irradiation IAS is non-inferior to CAS with respect to OS. IAS was suggested to be considered as the new standard of care for most patients with PSA recurrence after radical surgery. High-risk patients seem to be poor candidates for any type of androgen suppression. In summary, it can be concluded from the clinical trials that IAS is neither inferior nor superior to CAS, with respect to the end points, namely the time period until hormone-resistance as well as cancer-specific survival, but offers significant advantages in terms of adverse effects, quality of life and costs. Still, a number of important questions are remaining, regarding appropriate patient selection for therapy, optimum duration of therapy and exact scheduling of treatment reinstallation after the off-cycle. The offtreatment periods particularly hold the possibility to apply drugs such as finasteride or chemotherapeutics, in order to delay disease progression (Locke \& Bruchovsky, 2010). Moreover, the study has economic implications: patients in the IAS arm were on therapy only $27 \%$ of the time, reducing the cost of therapy significantly. 


\section{Side effects of androgen suppression therapy}

The well-known side effects of CAS like sexual dysfunction, hot flushes, fatigue, cardiovascular complications, osteoporosis, weight gain and anemia have significant implications for quality of life (Malone, et al., 2005; Freedland, et al., 2009; Galvão, et al. 2009). Since androgens are essential for the regulation of fat distribution, insulin sensitivity and lipid and bone metabolism, recent publications focussed on the concept that CAS may also be associated with an increase in overall and in particular cardiovascular morbidity and mortality (Corona, et al., 2011). A multivariate analysis by Saigal and colleagues evaluating over 22,000 men concluded that patients receiving CAS had a 20\% higher risk of cardiovascular morbidity (Saigal, et al., 2007). CAS leads to increased incidence of osteoporosis and concomitant bone fractures (Kiratli, et al., 2001). Therefore, it was expected that off-treatment periods during IAS would allow for recovery of testosterone levels and cessation of bone material degradation. With regards to bone loss, a large, retrospective study evaluated more than 50,000 men with prostate cancer, showing increased occurrence of bone fracture in the CAS group $(19.4 \%$ vs $12.6 \%)$. There was a significant relationship between the number of CAS doses and fracture risk (Shahinian, et al. 2005). In the elderly population of prostate cancer patients increased incidence of osteoporosis and resulting bone fractures are of major concern. Higano and colleagues observed loss of bone mineral density during 9 months of androgen suppression significantly greater than the expected $0.5 \%-1 \%$ annual loss in IAS; however, interruption of androgen suppression attenuated the rate of bone loss without full recovery (Higano, et al., 2004).

In the study by Malone and colleagues, general loss of potency occurred during the treatment period, but was regained by half of the evaluable patients when therapy was withdrawn (Malone, et al., 2005). There was no significant overall change in body mass index at the end of the treatment periods. Osteoporosis was documented for at least one site evaluated in one third of the patients. Quality of life and sexual function seem to follow testosterone normalization (Mearini, et al., 2011). Phase II clinical trials demonstrated improved sexual function and quality of life in men undergoing IAS (Dawson, 2000). The average percentage of time spent off androgen deprivation ranges from $37 \%-58 \%$ and most men were responsive to retreatment with hormonal therapy. While IAS seems feasible and holds the potential to improve quality of life of the patients, the degree of reversal of the long-term side effects of androgen suppression still remains to be confirmed.

\subsection{Bone matrix turnover and androgen suppression therapy}

Our group examined the effect of IAS on bone metabolism by determinations of CrossLaps levels, a biochemical marker of collagen degradation in blood samples of prostate cancer patients. These measurements revealed that increased bone degradation, which was associated with the androgen suppression phases, was rapidly reversed during treatment cessation periods, in good agreement with the clinical observations of reduced loss of bone mineral density (BMD) in IAS (Theyer, et al., 2010). 140 patients have been recruited since 1993, with first patients reaching their seventh treatment cycle (Theyer \& Hamilton, 1998). All patients with disseminated adenocarcinoma of the prostate fulfilling the inclusion criteria of a histologically confirmed tumor, stage $\geq \mathrm{T} 2$, not having received pretreatment by hormone ablation or chemotherapy and PSA $>6 \mathrm{ng} / \mathrm{ml}$ were recruited for a nonrandomized open IAS trial consisting of an initial 8 months course of androgen suppression (goserelin acetate/Zoladex ${ }^{\circledR}$ and cyproterone acetate/ Androcur ${ }^{\circledR}$ ), followed 
by treatment cessation and resuming of the therapy upon increases of PSA $>4$ and $>20$ $\mathrm{ng} / \mathrm{ml}$, respectively. Serum testosterone was measured using an ELISA assay (Biomar Diagnostics, Marburg, Germany) according to the manufacturer's instructions. PSA was determined by the microparticulate enzyme immunoassay (MEIA, AxSYM PSA assay, Abbott, USA). CrossLaps ELISA was obtained from Nordic Bioscience Diagnostics, Herlev, Denmark, and used according to the manufacturer's instructions (Rosenquist, et al., 1998). This assay is used for follow-up of anti-resorptive treatment of patients with metabolic bone diseases (Okabe, et al., 2004).

Amino-terminal propeptide of type I procollagen (PINP) and PSA were determined using the Elecsys 2010 Chemistry Analyzer (Roche Diagnostics, Vienna, Austria). All patients $(n=75$; mean age \pm SD: $68 \pm 7$ years, range: $53-84$ years) exhibited progression of disease without metastases following radical prostatectomy and/or irradiation therapy. The lengths of the treatment cessation periods (mean \pm SEM) for the respective off-treatment cycles (I-VI) in months were: $16 \pm 2(n=75), 10 \pm 1(n=31), 8 \pm 2(n=18), 8 \pm 1 \quad(n=12), 10 \pm 2(n=8), 7 \pm 6(n=2)$, respectively. The first treatment cessation period (PI) was significantly longer compared to the following breaks, which were not significantly different among each other. Individual time courses of testosterone and CrossLaps for a representative patient and four IAS cycles is depicted in figure $3 \mathrm{~A}$.

CrossLaps are elevated during androgen suppression phases indicating bone matrix degradation and normalize during treatment cessation periods on a regular basis (Theyer, et al., 2010). After a prolonged time without androgen suppression, CrossLaps values exhibited a gradual increase, most likely due to regrowth of the tumor (data not shown; Nguyen-Pamart, et al., 1997). Time courses of PINP and PTH were compared with PSA during the same IAS cycles in further measurements (figure 3B). The results show that PINP is a suitable alternative parameter for the assessment of bone matrix turnover during androgen suppression phases that are accompanied by low PSA levels. The parallel course of blood PTH indicates a participation of this hormone in androgen suppression-induced bone loss. This finding corroborates reports of decreased loss of BMD in bone scans in prostate cancer patients under IAS therapy. Since pretreatment concentrations of CrossLaps were restored within several months of therapy cessation and mean duration of the off-treatment periods ranged from 8-16 months in our patients, this protective effect of IAS is expected to be effective for several treatment cycles (Theyer, et al., 2010). The bone matrix synthesis product PINP was used to assess bone turnover in metastatic prostate and breast cancer among other malignancies (Jung, et al., 2011; Koopmans, et al., 2007; Pollmann, et al., 2007). Studies in metastatic prostate cancer patients showed that both PINP and ICTP (carboxy-terminal telopeptide of type I collagen) were most indicative of predicting metastatic progression and skeletal complications, respectively. Although androgen deprivation has been associated with bone loss in patients with prostate cancer, its mechanism remains unclear. The growth hormone (GH)/insulin-like growth factor-1 (IGF-1)/ parathyroid hormone (PTH) axis that plays a critical role in bone synthesis was investigated during CAS (Isahaya, et al., 2010). PTH is secreted by the chief cells of the parathyroid glands as a polypeptide containing 84 amino acids and effects to increase the concentration of calcium in blood (Poole \& Reeve, 2005). The serum PTH level was reduced after CAS by approximately $25 \%$ compared with baseline levels, concomitant with increases of bone resorption markers like blood and urinary N-telopeptides (NTx), in good agreement with our measurements during androgen suppression in IAS cycles. 
A

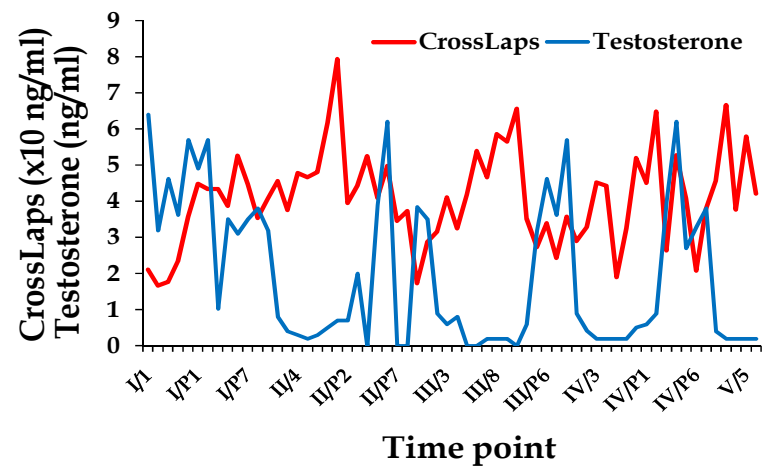

B

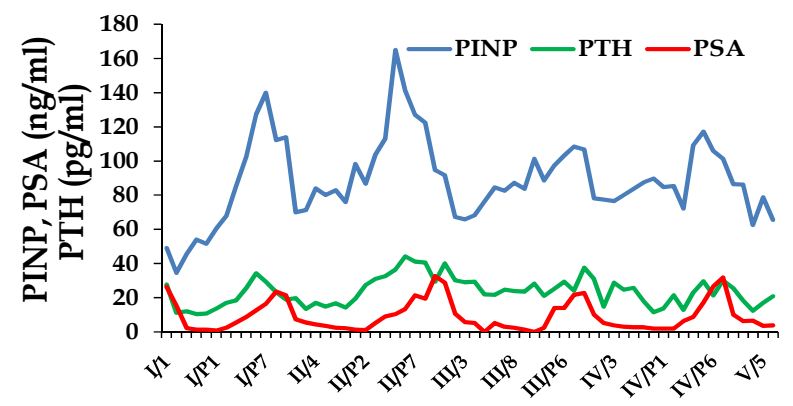

Time point

Fig. 3. (A) Individual time courses of testosterone and CrossLaps levels for a representative patient under IAS. Values cover androgen suppression phases (I-IV) and treatment cessation periods (I/P-IV/P). (B) Time courses of PSA, PINP and PTH are shown for the same patient.

\subsection{Anemia and intermittent androgen suppression}

Anemia was previously reported as a common side-effect of CAS. In an IAS study involving 95 patients receiving 245 cycles the median duration of resting periods was 8 months and median time to treatment failure 47 months (Malone et al., 2005). Testosterone recovery during treatment cessation was observed in $60 \%$ of cycles with mild anemia, which was more frequently detected in successive cycles $(33 \%, 44 \%$ and $67 \%)$. Thus, the observed anemia (hemoglobin level of $<30 \mathrm{~g} / \mathrm{l}$ ) was normochromic, normocytic, temporally related to the initiation of CAS and usually resolved after discontinuation of therapy in half of the cases. The improvement in hemoglobin during the off-treatment intervals probably contributes to improvements in the sense of well-being and vitality in these patients.

We collected data regarding anemia in our prostate cancer patients and a typical course of erythrocyte count, hemoglobin content and hematocrit is shown in figure 4 . The data show that small decreases and increases in erythrocyte parameters coincide with IAS phases and levels of PSA. Such determinations can be used to assess the extent of anemia and the impact of treatment cessations on erythropoiesis. 
A

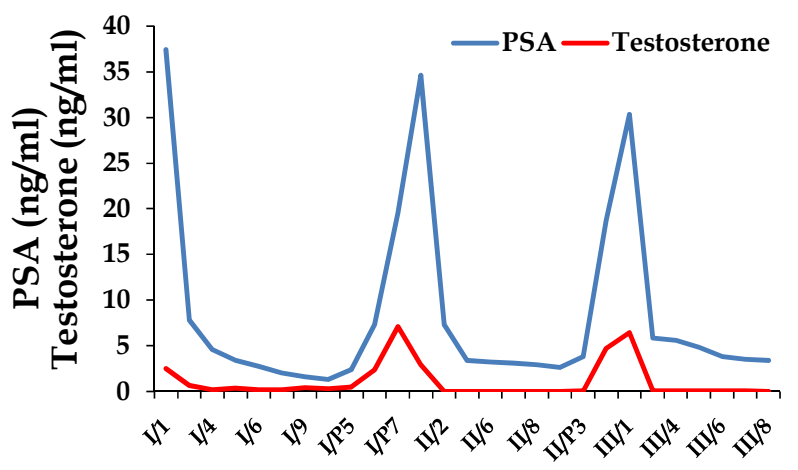

B

Time point

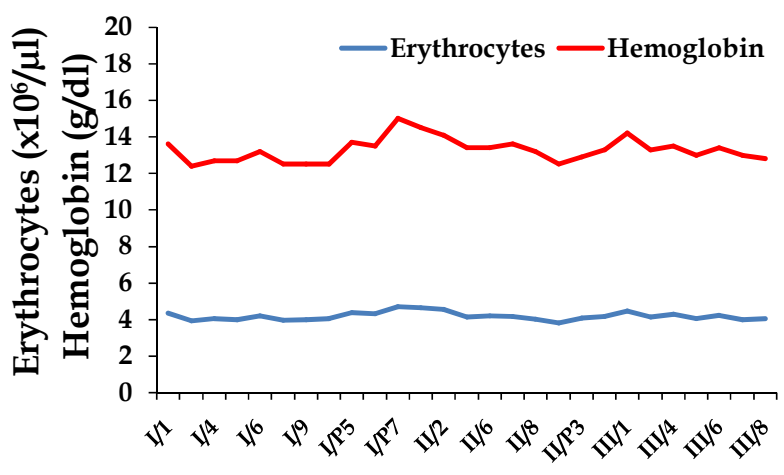

Time point

C

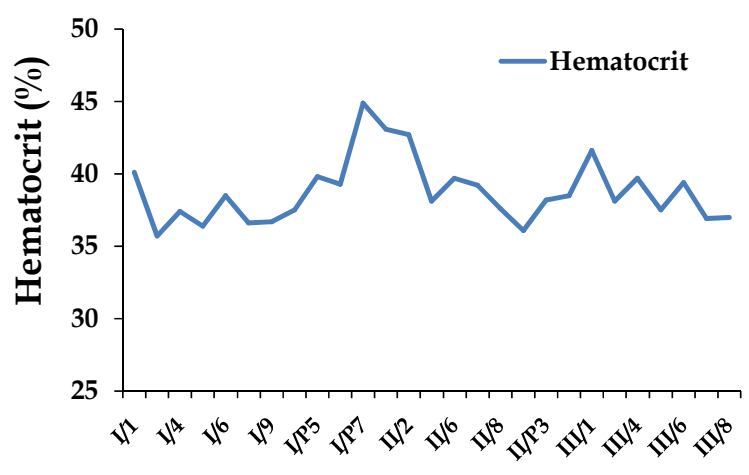

Time point

Fig. 4. (A) Time courses of testosterone and PSA, (B), hemoglobin and erythrocyte count and (C) and hematocrit are shown for 3 cycles of IAS for a typical prostate cancer patient. 


\section{Conclusions}

In the past 25 years, IAS has developed from an unproven theoretical framework to a promising therapeutic option for subgroups of prostate cancer patients equal to CAS in respect to overall survival. Many questions in regard to the most suitable patient population and the optimal application of IAS remain to be investigated. With the exception of the frequency of hot flashes the improvement of other side effects of androgen suppression by intermittent therapy needs further careful assessment. This can be supported by determination of laboratory parameters of bone matrix turnover, blood chemistry and lipid profiles and correlation with the clinical characteristics. Last but not least, the reduced costs of intermittent therapy are expected to promote a more general application.

\section{References}

Abrahamsson, P.A. (2010) Potential Benefits of Intermittent Androgen Suppression Therapy in the Treatment of Prostate Cancer. Eur Urol 57(1), 49-59.

Akakura, K., Bruchovsky, N., Goldenberg, S.L., Rennie, P.S., Buckley, A.R. \& Sullivan L.D.(1993) Effects of intermittent androgen suppression on androgen-dependent tumors. Apoptosis and serum prostate-specific antigen. Cancer 71(9), 2782-2790.

Akakura, K., Bruchovsky, N., Rennie, P.S., Coldman, A.J., Goldenberg, S.L., Tenniswood, M. \& Fox, K. Effects of intermittent androgen suppression on the stem cell composition and the expression of the TRPM-2 (clusterin) gene in the Shionogi carcinoma. $J$ Steroid Biochem Mol Biol 59(5-6), 501-511.

Bales, G.T., Sinner, M.D., Kim, J.H. \& Chodak, G.W. (1996) Impact of intermittent androgen deprivation on quality of live (QOL). J Urol 155, 578A.

Brawer, M.K. (2006) Hormonal therapy for prostate cancer. Rev Urol 8, S35-47.

Bruchovsky, N., Rennie, P.S., Coldman, A.J., Goldenberg, S.L., To, M. \& Lawson, D. (1990) Effects of androgen withdrawal on the stem cell composition of the Shionogi carcinoma. Cancer Res 50(8), 2275-2282.

Bruchovsky, N., Rennie, P.S., Otal, N., Vanson, A., Giles, M. \& Pontifex, H. (1985) Variability of androgen-related phenotypes in the Shionogi mammary carcinoma during growth, involution, recurrence, and progression to hormonal independence. Cancer Res 45(2), 682-689.

Bruchovsky, N., Snoek, R., Rennie, P.S. Akakura, K., Goldenberg, L.S. \& Gleaves, M. (1996) Control of tumor progression by maintenance of apoptosis. Prostate 6S, 13-21.

Bruchovsky, N., Rennie, P.S., Van Doom, E. \& Noble, R.L. (1978) Pathological growth of androgen-sensitive tissues resulting from the latent actions of steroid hormones. $J$ Toxicol Environ Health 4, 391-408.

Buchan, N. C. \& Goldenberg, S.L. (2010) Intermittent androgen suppression for prostate cancer. Nature Rev Urol 7, 552-560.

Bruchovsky, N., Goldenberg, S.L., Rennie, P.S. \& Gleaves, M. (1995) Theoretical considerations and initial clinical results of intermittent hormone treatment of patients with advanced prostatic carcinoma. Urologe-A 34, 389-392.

Calais da Silva, F.E., Bono, A.V., Whelan, P., Brausi, M., Marques Queimadelos, A., Martin, J.A., Kirkali, Z., Calais da Silva, F.M. \& Robertson, C. (2009) Intermittent androgen deprivation for locally advanced and metastatic prostate cancer: results from a 
randomised phase 3 study of the South European Uroncological Group. Eur Urol 55(6), 1269-1277.

Chang, S.S., \& Kibel, A.S. (2009) The role of systemic cytotoxic therapy for prostate cancer. BJU Int 103, 8-17.

Corona, G., Baldi, E. \& Maggi, M. (2011) Androgen regulation of prostate cancer: Where are we now? J Endocrinol Invest 34(3), 232-243.

Dawson, N.A. (2000) Intermittent androgen deprivation. Curr Oncol Rep 2(5), 409-416.

Fitzpatrick, J.M., Schulman, C., Zlotta, A.R. \& Schroeder, F.H. (2009) Prostate cancer: a serious disease suitable for prevention. BJU Int 103, 864-870.

Freedland, S.J., Eastham, J. \& Shore, N. (2009) Androgen deprivation therapy and estrogen deficiency induced adverse effects in the treatment of prostate cancer. Prostate Cancer Prostatic Dis 12(4), 333-338.

Galvão, D.A., Taaffe, D.R., Spry, N., Joseph, D. \& Newton, R.U. (2009) Cardiovascular and metabolic complications during androgen deprivation: exercise as a potential countermeasure. Prostate Cancer Prostatic Dis 12(3), 233-240.

Gjertson, C.K. \& Albertsen, P.C. (2011) Use and assessment of PSA in prostate cancer. Med Clin North Am 95(1), 191-200.

Gleave, M.E, Goldenberg, S.L., Jones, E.C., Bruchovsky N. \& Sullivan L.D. (1996) Maximal biochemical and pathological downstaging requires eight months of neoadjuvant hormonal therapy prior to radical prostatectomy. J Urol 155, 213-219.

Gleave, M., Bruchovsky, N., Goldenberg, S.L. \& Rennie, P. (1998) Intermittent androgen suppression for prostate cancer: rationale and clinical experience. Eur Urol 34, Suppl 3, 37-41.

Gleave, M., Santo, N., Rennie, P.S., Goldenberg, S.L., Bruchovsky, N. \& Sullivan, L.D. (1996) Hormone release and intermittent hormonal therapy in the LNCaP model of human prostate cancer. Prog Urol 6(3), 375-385.

Goldenberg, S.L., Bruchovsky, N., Gleave, M.E., Sullivan, L.D. \& Akakura, K. (1995) Intermittent androgen suppression in the treatment of prostate cancer: A preliminary report. Urology 47, 956-961.

Grossmann, M., Hamilton, E.J., Gilfillan, C., Bolton, D., Joon, D.L. \& Zajac, J.D. (2011) Bone and metabolic health in patients with non-metastatic prostate cancer who are receiving androgen deprivation therapy. Med J Aust 194(6), 301-306.

Higano, C., Shields, A., Wood, N., Brown, J. \& Tangen, C. (2004) Bone mineral density in patients with prostate cancer without bone metastases treated with intermittent androgen suppression. Urology 64, 1182-1186.

Higano, C.S., Ellis, W., Russell, K. \& Lange, P.H. (1996) Intermittent androgen suppression with leuprolide and flutamide for prostate cancer. Urology 48: 800.

Huggins, D. \& Hodges, C.V. (1941) Studies on prostatic cancer. I. The effect of castration, of estrogen and of androgen injection on serum phosphatases in metastatic carcinoma of the prostate. Cancer Res 1:293-297.

Isahaya, E., Hara, N., Nishiyama, T., Hoshii, T., Takizawa, I. \& Takahashi, K. (2010) Bone metabolic disorder in patients with prostate cancer receiving androgen deprivation therapy (ADT): impact of ADT on the growth hormone/insulin-like growth factor1/parathyroid hormone axis. Prostate 70(2), 155-161.

Jadvar, H. (2011) Prostate cancer. Methods Mol Biol 727, 265-290. 
Jung, K., Miller, K., Wirth, M., Albrecht, M. \& Lein, M. (2011) Bone turnover markers as predictors of mortality risk in prostate cancer patients with bone metastases following treatment with zoledronic acid. Eur Urol 59(4), 604-612.

Kiratli, B.J., Srinivas, S., Perkash, I. \& Terris, M.K. (2001) Progressive decrease in bone density over 10 years of androgen deprivation therapy in patients with prostate cancer. Urology 57, 127-132.

Klotz, L.H., Herr, H.W., Morse, M.J. \& Whitmore, W.F. (1986) Intermittent endocrine therapy for advanced prostate cancer. Cancer 58, 2546-2550.

Klotz, L., O'Callaghan, C.J., Ding, K., Dearnaley, D.P., Higano, C.S., Horwitz, E.M., Malone, S., Goldenberg, S.L., Gospodarowicz, M.K. \& Crook, J.M. (2011) A phase III randomized trial comparing intermittent versus continuous androgen suppression for patients with PSA progression after radical therapy: NCIC CTG PR.7/SWOG JPR.7/CTSU JPR.7/UK Intercontinental Trial CRUKE/01/013. J Clin Oncol 29, S7; Abstract \# 3.

Kollmeier, M.A. \& Zelefsky, M.J. (2008) What is the role of androgen deprivation therapy in the treatment of locally advanced prostate cancer? Nat Clin Pract Urol 5, 584-585.

Koopmans, N., de Jong, I.J., Breeuwsma, A.J. \& E. van der Veer, E. (2007) Serum bone turnover markers (PINP and ICTP) for the early detection of bone metastases in patients with prostate cancer: a longitudinal approach. J Urol 178, 849-853.

Lassi, K. \& Dawson, N.A. (2009) Emerging therapies in castrate-resistant prostate cancer. Curr Opin Oncol 21, 260-265.

de Leval, J., Boca, P., Yousef, E., Nicolas, H., Jeukenne, M., Seidel, L., Bouffioux, C., Coppens, L., Bonnet, P., Andrianne, R. \& Wlatregny, D. (2002) Intermittent versus continuous total androgen blockade in the treatment of patients with advanced hormone-naive prostate cancer: results of a prospective randomized multicenter trial. Clin Prostate Cancer 1(3), 163-171.

Locke, J.A. \& Bruchovsky, N. (2010) Prostate cancer: finasteride extends PSA doubling time during intermittent hormone therapy. Can J Urol 7(3), 5162-5169.

Madan, R.A., Pal, S.K., Sartor, O. \& Dahut, W.L. (2011) Overcoming chemotherapy resistance in prostate cancer. Clin Cancer Res 17(12), 3892-3902.

Malone, S., Perry, G., Segal, R., Dahrouge, S. \& Crook, J. (2005) Long-term side-effects of intermittent androgen suppression therapy in prostate cancer: results of a phase II study. BJU Int 96, 514-520.

Mearini, L., Zucchi, A., Costantini, E., Bini, V. \& Porena, M. (2011) Intermittent androgen suppression in prostate cancer: testosterone levels and its implication. J Sex Med $8(4), 1218-1227$.

Mellado, B., Codony, J., Ribal, M.J., Visa, L. \& Gascon, P. (2009) Molecular biology of androgen-independent prostate cancer: the role of the androgen receptor pathway. Clin Transl Oncol 11, 5-10.

Mottet, N., Prayer-Galetti, T., Hammerer, P., Kattan, M.W. \& Tunn, U. (2006) Optimizing outcomes and quality of life in the hormonal treatment of prostate cancer. BJU Int 98, 20-27.

Nguyen-Pamart, M., Caty, A., Feutrie, M.L., Fournier, E., Gosselin, P. \& Mazeman, E. (1997) The diagnostic value of urinary CrossLaps and serum alkaline phosphatase in patients with prostate cancer. BJU 80, 452-455. 
Okabe, R., Inaba, M., Nakatsuka, K., Miki, T., Naka, H., Moriguchi, A. \& Nishizawa, Y. (2004) Significance of serum CrossLaps as a predictor of changes in bone mineral density during estrogen replacement therapy; comparison with serum carboxyterminal telopeptide of type I collagen and urinary deoxypyridinoline. $J$ Bone Miner Metab 22, 127-131.

Pollmann, D., Siepmann, S., Geppert, R., Wernecke, K.D., Possinger, K. \& Lüftner, D. (2007) The amino-terminal propeptide (PINP) of type I collagen is a clinically valid indicator of bone turnover and extent of metastatic spread in osseous metastatic breast cancer. Anticancer Res 27(4A), 1853-1862.

Poole, K. \& Reeve, J. (2005). Parathyroid hormone - a bone anabolic and catabolic agent. Curr Opin Pharmacol 5(6): 612-617.

Raghavan, D., Koczwara, B. \& Javle, M. (1997) Evolving strategies of cytotoxic chemotherapy for advanced prostate cancer. Eur J Cancer 33, 566-574.

Rennie, P.S., Bruchovsky, N., Buttyan, R., Benson, M. \& Cheng, H. (1988) Gene expression during the early phases of regression of the androgen-dependent Shionogi mouse mammary carcinoma. Cancer Res 48(22), 6309-6312.

Rennie, P.S., Bruchovsky, N. \& Coldman, A.J. (1990) Loss of androgen dependence is associated with an increase in tumorigenic stem cells and resistance to cell-death genes. J Steroid Biochem Mol Biol 37(6), 843-847.

Rennie, P.S, Bruchovsky, N., Akakura, K., Goldenberg, S.L., Otal, N., Akakura, S., Wong, P. \& Tenniswood, M. (1994) Effect of tumour progression on the androgenic regulation of the androgen receptor, TRPM-2 and YPT1 genes in the Shionogi carcinoma. J Steroid Biochem Mol Biol 50(1-2), 31-40.

Rosenquist, C., Fledelius, C., Christgau, S., Pedersen, B.J., Bonde, M., Qvist, P. \& Christiansen, C. (1998) SerumCrossLaps ${ }^{\circledR}$ ELISA. First application of monoclonal antibodies for measurement in serum of bone-related degradation products from C-terminal telopeptides of type I collagen. Clin Chem 44, 2281-2289.

Saigal, C.S., Gore, J.L., Krupski, T.L, Hanley, J., Schonlau, M. \& Litwin, M.S. (2007) Androgen deprivation therapy increases cardiovascular morbidity in men with prostate cancer. Cancer 110(7), 1493-1500.

Sciarra, A., Cattarino, S., Gentilucci, A., Alfarone, A., Innocenzi, M., Gentile, V. \& Salciccia, S. (2011) Predictors for response to intermittent androgen deprivation (IAD) in prostate cancer cases with biochemical progression after surgery. Urol Oncol, in press.

Seruga, B. \& Tannock, I.F. (2008) Intermittent androgen blockade should be regarded as standard therapy in prostate cancer. Nat Clin Pract Oncol 5, 574-576.

Shahinian, V.B., Kuo, Y.F., Freeman, J.L. \& Goodwin, J.S. (2005) Risk of fracture after androgen deprivation for prostate cancer. N Engl J Med 352(2), 154-164.

da Silva, F.C. (2011) Intermittent hormonal therapy for prostate cancer. Curr Opin Urol 21(3), 248-251.

Snoek, R., Cheng, H., Margiotti, K., Wafa, L.A., Wong, C.A., Wong, E.C., Fazli, L., Nelson, C.C., Gleave, M.E. \& Rennie, P.S. (2011) In vivo knockdown of the androgen receptor results in growth inhibition and regression of well-established, castrationresistant prostate tumors. Clin Cancer Res 15(1), 39-47.

Spry, N.A., Galvão, D.A., Davies, R., La Bianca, S., Joseph, D., Davidson, A. \& Prince, R. Long-term effects of intermittent androgen suppression on testosterone recovery 
and bone mineral density: results of a 33-month observational study. BJU Int 104(6), 806-812.

Strum, S.B., Scholz, M.C. \& McDermed, J.E. (2000) Intermittent androgen deprivation in prostate cancer patients: Factors predictive of prolonged time off therapy. Oncologist 5, 45-52.

Taylor, L.G., Canfield, S.E. \& Du, X.L. (2009) Review of major adverse effects of androgendeprivation therapy in men with prostate cancer. Cancer 115, 2388-2399.

Theyer, G., Holub, S., Dürer, A., Andert, S., Haberl, I., Theyer, U. \& Hamilton, G. (1997) Measurements of tissue polypeptide-specific antigen in prostate cancer patients under intermittent androgen suppression therapy. Br J Cancer 75, 1515-1518.

Theyer, G. \& Hamilton G. (1998) Current status of intermittent androgen suppression in the treatment of prostate cancer. Urology 53, 353-359.

Theyer, G., Dürer, A., Theyer, U., Haberl, I., Ulsperger, E., Baumgartner, G. \& Hamilton, G. (1999) Measurements of free and total PSA, tissue polypeptide-specific antigen (TPS), and CYFRA 21-1 in prostate cancer patients under intermittent androgen suppression therapy. Prostate 41: 71-77.

Theyer, G., Ulsperger, E., Baumgartner, G., Raderer, M. \& Hamilton, G. (2000) Prolonged response to a single androgen suppression phase in a subpopulation of prostate cancer patients. Ann Oncol 11, 877-881.

Theyer, G., Holub, S., Olszewski, U. \& Hamilton, G. (2010) Measurement of bone turnover in prostate cancer patients receiving intermittent androgen suppression therapy. OA $J$ Urology 2, 155-159.

Tzou, K., Tan, W.W. \& Buskirk, S. (2011) Treatment of men with rising prostate-specific antigen levels following radical prostatectomy. Expert Rev Anticancer Ther 11(1), 125-136.

Yu, E.Y., Gulati, R., Telesca, D., Jiang, P., Tam, S., Russell, K.J, Nelson, P.S., Etzioni, R.D. \& Higano, C.S. (2010) Duration of first off-treatment interval is prognostic for time to castration resistance and death in men with biochemical relapse of prostate cancer treated on a prospective trial of intermittent androgen deprivation. J Clin Oncol 28(16), 2668-2673. 


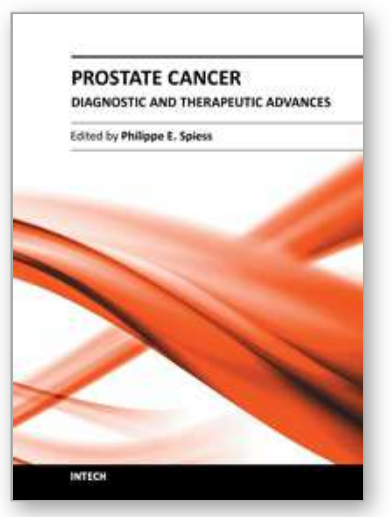

\section{Prostate Cancer - Diagnostic and Therapeutic Advances}

Edited by Dr. Philippe E. Spiess

ISBN 978-953-307-319-4

Hard cover, 378 pages

Publisher InTech

Published online 25, November, 2011

Published in print edition November, 2011

In this book entitled "Prostate Cancer - Diagnostic and Therapeutic Advances", we highlight many of the significant advances made in our treatment armamentarium of prostate cancer. The book is subdivided into four sections termed: 1) novel diagnostic approaches, 2) surgical treatments options, 3) radiation therapy and its potential sequelae, and 4) medical management and its treatment complications. After reading the present book, readers will be very familiar with the major clinical advances made in our multifaceted treatment approach to prostate cancer over the past decade. This book is a tribute to our pioneering urologists and allied healthcare professionals who have continually pushed forward our traditional therapeutic envelope.

\section{How to reference}

In order to correctly reference this scholarly work, feel free to copy and paste the following:

Gerhard Hamilton, Ulrike Olszewski-Hamilton and Gerhard Theyer (2011). Intermittent Androgen Suppression Therapy for Prostate Cancer Patients: A Choice for Improved Quality of Life?, Prostate Cancer - Diagnostic and Therapeutic Advances, Dr. Philippe E. Spiess (Ed.), ISBN: 978-953-307-319-4, InTech, Available from: http://www.intechopen.com/books/prostate-cancer-diagnostic-and-therapeutic-advances/intermittentandrogen-suppression-therapy-for-prostate-cancer-patients-a-choice-for-improved-quality

\section{INTECH}

open science | open minds

\section{InTech Europe}

University Campus STeP Ri

Slavka Krautzeka 83/A

51000 Rijeka, Croatia

Phone: +385 (51) 770447

Fax: +385 (51) 686166

www.intechopen.com

\section{InTech China}

Unit 405, Office Block, Hotel Equatorial Shanghai

No.65, Yan An Road (West), Shanghai, 200040, China

中国上海市延安西路65号上海国际贵都大饭店办公楼405单元

Phone: +86-21-62489820

Fax: +86-21-62489821 
(C) 2011 The Author(s). Licensee IntechOpen. This is an open access article distributed under the terms of the Creative Commons Attribution 3.0 License, which permits unrestricted use, distribution, and reproduction in any medium, provided the original work is properly cited. 